\title{
Research Patterns and Research Libraries: What Should Change?
}

\section{Peter S. Graham}

A paper by Francis Miksa has suggested that because research patterns have changed, the services provided by research libraries must change to match them. But the research patterns must be evaluated as well as described. Before major changes in research libraries are initiated, we must define our goals and relate our activities to them as well as to present research patterns. Research libraries need not adapt to all research patterns.

If it walks like a duck, talks like a duck, looks like a duck-it must be a duck.-Proverb

Why a duck?-Chico Marx

How are research libraries responding to the needs of today's researchers? How should they respond? These questions beg many more, not the least of which is, Why do we do what we do? Early in 1987, Francis L. Miksa, an OCLC Visiting Scholar and library school professor, gave an important speech to a conference of research library directors which OCLC has produced as Research Patterns and Research Libraries. ${ }^{1}$ In this paper he suggests that research patterns have changed significantly since World War II and that research libraries must change in certain ways as well.

Miksa's discussion is concise, stimulating, and coherent. One of his essay's great merits is its clarity of presentation about truths in university research that libraries need to contend with. They are not, however, the only truths, as will be developed here. In addition, his conclusions need to be debated. They speak only of procedure and do not address underlying assumptions and values of our profession; yet it is there that the debate must begin. In this paper, I will begin by reviewing and discussing Miksa's major points. In what follows I then hope to suggest the jumpingoff point for questions such as, Should libraries only react to changes in their environment, or attempt to act upon that environment? If research patterns and research libraries are not in harmony, what should change? What are our goals?

\section{A VIEW OF RESEARCH PATTERNS}

Miksa's Research Patterns and Research Libraries rests on the contrast between what research activity is presently like and what research libraries presently provide; some specific recommendations are presented. His first section describes late twentiethcentury research patterns, which are subsumed under three headings.

1. Research method as much more quantitative: Research has become more formally analytic than it was in the past. The research process is highly structured, quantitative methods are more generally employed, and the computer has become central.

2. Professionalization of research: Research has become a socially accepted occupational status. Where the rewards used to be recognition of scholarliness, now they are

Peter S. Graham is Associate University Librarian for Technical and Automated Services at Rutgers University, New Brunswick, New Jersey 08903. 
the more worldly forms of status: group leadership, travel, grant funds, and salary. Research is now preeminently a team process, driven by funding agencies, and primarily applied (rather than pure).

3. Research as information flow: Research, because it is increasingly quantitative and analytic, increasingly uses data from other studies (and passes data on to more), rather than using and passing on formal written documents. Communication between team members is increasingly informal and quick, with concomitant growth in the role of gatekeeper. Because most research is applied, most disciplinary boundaries are blurred. Reports of research now serve funding and status functions, often reducing their value for further research and contributing to the sense that a complete literature review is not necessary.

This theme of the shifts in research methodology was also developed for librarians several years ago in an important book by Charles Osburn, Academic Research and Library Resources. ${ }^{2}$ In similar terms, Osburn carefully described the shift in research emphasis, especially since World War II, and how this shift has affected collection development in research libraries. Some of his points included the enormous effect of governmental policies and funding on research structures and goals, the transfer of scientific organizational patterns to the social sciences, and the increased demand for research to solve specific social problems.

\section{A VIEW OF RESEARCH LIBRARIES}

Miksa's paper characterizes two views historically held by research libraries as having come to hamper their proper performance today. First is the assumption research libraries tend to make of "the centrality of the idea of a universe of knowledge." ${ }^{3}$ Second is the assumed "chief task" of the current research library, which "in relationship to research is to provide access to documents. ${ }^{\prime 4}$ Both descriptions of research library views are important, and the insights drawn from them are stimulating. Both of them, I believe, need further discussion before we can accept or reject these characterizations.

\section{Research Libraries and the Universe of Knowledge}

Miksa amplifies his first point, that of research libraries assuming a universe of knowledge, by saying that

The very core of a universe-of-knowledge point of view is the assumption that all knowledge, whether old or new, is by its very nature a single, cohesive, interwoven whole.

Knowledge is, in fact, a unity, a superstructure of all things known that, whether evident or not, is naturally ordered or classified in terms of its branches or disciplines, subbranches or subdisciplines, etc. $^{5}$

New knowledge is, in this view, not only a direct product of the old but necessarily becomes a part of the overall unity of knowledge.

\section{"Research has become nondisci- plinary. That is, disciplinary struc- ture is simply not at issue in the re- search process."}

In a stimulating passage, the essay describes contemporary research (in the aforementioned patterns) as fragmenting the world of knowledge. "Research has in fact become increasingly problemoriented rather than discipline-oriented." Where some have called much modern research interdisciplinary,

what has really occurred is that research has become nondisciplinary. That is, disciplinary structure is simply not at issue in the research process.... Research has become incredibly selective, pragmatic and throw-away in its uses of knowledge. Another way to say this is that research does not need to be aware of the idea of the universe of knowledge to proceed. Research does not even much need the universe of knowledge organized at all. ...6

This is a brilliant description, and much of it is apparently true. The truly unfortunate aspect of the argument is that it accepts the new nondisciplinary research behavior as a norm and urges that research libraries accommodate to it. The earlier sympathetic description of the universe of knowledge could easily lead one 
to think that Miksa considers this view correct and valuable; but without a demurring word, he appears ready to discard it in order to serve those for whom organized knowledge is not a value.

\section{Whose Knowledge}

\section{Is in Which Universe?}

There is a prior problem with the argument at this point; it is in the description of the universe-of-knowledge point of view that is ascribed to research libraries. In fact, the idea of human knowledge as a unity, "a superstructure of all things known," does not hold up well, either philosophically or in practice. I should rather say that it holds up philosophically only in nonreligious thinking, for of course it is fundamental to (for example) Buddhist or neo-Platonic thought that the universe is one in all respects, and that our knowledge of it must mirror that oneness.

The modern western philosophical tradition is considerably more humble; we hear little of philosophies that claim to encompass all knowledge and to explain all phenomena (even serious Marxists have been quiet on this score for some time). The physicists, to take science as an example, acknowledge that classical scientific method fails before fundamental structures of energy and matter: we simply don't know (and evidently can't know) what happens in any given interaction, and must project with the aid of statistics. There may yet be a Grand Unified Theory; Einstein thought there was, and Hawking thinks there is, but there was a long stretch in between when the idea was belittled. The deconstructionists, to take the humanities, tell us that our understanding of what we read is fundamentally flawed and probably solipsistic; whatever the author meant is not likely to be what we read. Right or wrong, this approach does not tell us that knowledge is a unity.

In terms familiar to librarianship, the proposition of a structured universe of knowledge can be seen to be in difficulty if we consider such disparate evidence as Thomas Kuhn's work and creationism.

Kuhn's Structure of Scientific Revolutions makes clear that, far from all knowledge being a unity, knowledge leads to an understanding of disunity: as knowledge is accumulated in science, it more and more leads to a realization of the disparity between what is known and what was previously understood. ${ }^{7}$ Eventually the disparity becomes intellectually too much to bear and a paradigm shift occurs, sometimes with great intellectual and even political upheaval. A whole body of what was considered knowledge becomes "known" to be error, or at the least to be interpreted quite differently. To understand Kuhn's approach is to understand the ephemerality of worldviews and of a structured universe of knowledge. Libraries often, it is true, have collected as if there were a structured universe of knowledge; given the changes in worldviews over the generations, the result is that in our house there are many mansions.

At a more practical level, the recent debate in a popular library journal on where to classify creationism points up the way in which libraries do not today simply regard knowledge as a single unity. Knowledge is in the eyes of the beholder: there are creationists who deny the Darwinian view and the rest of us who regard creationism not as a matter of knowledge but as a way of thinking. Each, however, deserves and requires its place in collections representing human thought and culture. So do materials on geocentrism, spoon bending, racism, and the occult; the papacy and atheism; scientific socialism and supply-side economics; catastrophism and Gondwanaland. An unfortunate conclusion can be drawn from the proposition that human knowledge is a unity on which libraries focus; it is that libraries should collect only the truth.

Miksa tells us he has done considerable work in classification theory. ${ }^{8}$ It may have led him astray. Dewey and the other nineteenth-century synthesizers gave us mechanisms which purport to encompass human knowledge. The misleading comprehensiveness of our classifications, and of our subject thesauri, can lead the unwary to see a theoretical structure behind them; in the end these are only attempts, brave and helpful but inevitably futile, to describe what has come over the intellectual transom in all its marvelous variety.

The fact remains that research libraries have collected comprehensively whether 
or not their librarians have had a view about a unified structure of knowledge. It is correct to indicate that this breadth of collection has been a distinguishing characteristic of the great research library in the past. As suggested earlier, Miksa apparently is ready to replace this distinction in order better to serve those who wish to work on the particularities of the moment.

\section{Research Libraries and Documentation}

The second view within research libraries that is said to hamper their performance is their commitment to providing access to documents. Librarians are apparently misled in two ways: first, they erroneously believe that documents are a primary information input in the research process. Second, librarians mistakenly believe that they need only supply access to documents, whereas they should somehow be providing the documents themselves. This combination of errors has, for the past decade, led us down the primrose path of online catalogs, bibliographic networks, and the distributed national library.

\section{"Teamwork and collegial networks, particularly in an electronic mode, are causing researchers to use infor- mal reports and only the data from prior studies rather than published research outcomes."}

Part of the analysis is persuasive as to why much current research is not oriented toward documents. First, teamwork and collegial networks, particularly in an electronic mode, are causing researchers to use informal reports and only the data from prior studies rather than published research outcomes. Second, present research is oriented toward a specific problem at hand, obviating the need to review the literature fully if a solution to the problem can be found without doing so.

Third, and most important, "the most urgent need facing the research information flow process is that of information management at the point of use." In other words, there is too much information. In- formation management means a filtering and organizational process; and (in a statement with appalling implications for the state of contemporary scholarship) "the chief difficulty here is that the researcher . . . has neither the time, the inclination, nor the skill to do this. . . .,

It would have been helpful to have had a more consistent use of the term document. In the discussion of research patterns it reasonably appeared to mean the representation of information in any of a variety of forms, including electronic; but when Miksa is criticizing the libraries' orientation, he says that "documents are, after all, physical materials." ${ }^{11}$ Having set up this straw man, he then describes libraries as only concerned with providing access to physical objects that they can count and control (i.e., printed volumes). This fairly assesses the mind-set of some librarians, but no longer of the majority of leading research librarians. For years now many of use have been providing information retrieval services and experimenting with telefacsimile, not to mention countless referrals to other sources for information not held locally. On campus after campus libraries and computer centers are meeting to discuss how to use the institution's computing facilities and information skills to provide patrons with the research information they need-not just documentsregardless of the form in which it exists. $^{12,13}$

For most research librarians a document is no longer defined simply as a physical item owned by a given library, though it certainly helps to know where a copy might be. A more interesting discussion of what libraries should now provide might be centered around a more precise definition of document-one that doesn't depend on physical manifestation. The issue has come up recently in a number of forums of librarians grappling with how to provide machine-readable data to college and university patrons. The differences expressed on this issue represent in miniature the issues facing librarianship at large. For example, participants in the Research Libraries Group (RLG) experiment funded by the Pew Foundation met at San Antonio in 1987 to share experiences. One difference between institutions was what 
machine-readable data files (MRDFs) were included in their catalog. Some institutions only included MRDFs that were fully documented and distributed by a recognized agency; on the other hand, some included work in progress and recently developed programs by local faculty members.

Increasingly, there has been an understanding that electronic information can include the same full range of unpublished, prepublished, and published work as print materials. One proposal that makes sense has been for libraries to provide access only to electronic information represented by published work, much as we have traditionally done for print (and other nonprint) materials. The definition of publication must be rediscussed to take into account new circumstances, but surely it will include matters such as formal dissemination, multiplicity of copies, consistent or standard format, selfdocumentation, authorship responsibility, and the nature of the publishing agency. (Other influential practitioners, such as Peggy Seiden of Carnegie-Mellon University's software project, think that such a definition is unnecessarily constraining.)

It certainly makes sense for a library to provide access to prepublished data in some way (e.g., the RLG joint project with the Modern Language Association). Miksa is advocating that a research library has a responsibility to provide access to gestating research in the same way it does for what have classically been the products of research. Such a position has implications for the acquisition and preservation of the intellectual record. There are also serious implications for the resources that must be diverted from other library purposes, for the patron and for the library professional, and for the research process itself. Here are issues that need discussion in and beyond the profession, and that will shed light on whether document provision is truly a limiting feature for present research libraries.

\section{ARGUABLE CONCLUSIONS}

The conclusions of Miksa's paper derive from "the need to adopt a revised perspective about research patterns" in order "to shape technology and research library goals. ${ }^{\prime 14}$ First, to replace the view that there is a universe of knowledge, libraries and librarians must change their approach to match the world of research. If research is indeed nondisciplinary, but research libraries continue to assume the interrelationship of disciplines implied by the universality of knowledge, then libraries are working at cross-purposes with those using them. Libraries (and librarians) should, therefore, focus their resources to "more closely match the research actually being done rather than ideal coverage of the entire structure of knowledge" or of any of its sectors. One approach is to move to demand-driven acquisition in place of long-range collecting plans. ${ }^{15}$

Second, to replace the emphasis on document access, library personnel must radically change the work they do in order to perform "information management" for research projects. Libraries should, in some active way, be providing the texts themselves, not simply access to the texts. And not only should the library mechanisms provide full texts, but librarians should become part of the research teams. Given a view of present research as team oriented, working most often on applied topics with the need to eliminate unwanted material as much as to find necessary information, librarians should be seconded to the teams to do this work: "I. . . mean distributed personnel whose task must be done in the context of the research activity, not simply personnel who look in on research efforts now and then. ${ }^{16}$

These are recommendations to change fundamentally the way research libraries and research librarians work: research libraries should eschew being libraries of record, and research librarians should take on entirely new tasks. But properly to found such recommendations, there must first be a discussion of goals and their concomitant values; to my perception these are absent from Miksa's paper. Goals and values must now be introduced.

The first thing that must be said is that Miksa's picture of research is very depressing. We see an academe full of narrow opportunists who seldom generalize as they maneuver for the main chance. The universities are apparently full (and 
only for the past few decades, not before) of researchers too timid to spread their wings fully and who depend excessively on each other as they work to ameliorate problems of little lasting import. Researchers as a class are either ignorant or untrained in reviewing the literature of their own field as an integral part of their own work, and they do not think it necessary.

Is it true? I doubt it. In this account Ilook in vain for figures like Paul Oskar Kristeller, Lewis Thomas, Alice Ostriker, Richard Feynman, Richard Ellman, Stanley Schoenbaum, James Watson, Susan Gubar, Oscar Handlin, Barbara McClintock, or E. P. Thompson. Is it really true that our civilization's scholars have neither "the time, the inclination, nor the skill" to do their own work?

\section{"As research librarians we must take the stand that it is indeed important for national research collections to be built that aim at comprehensiveness, whether or not we call it an 'ideal cov- erage of the entire structure of knowl- edge.' "}

Related to this depressing view of research is that it is an undifferentiated one. The term is always research not some research. The term is never qualified in the paper: apparently there are no differences between past and present research, between scientific and humanistic, or between fundamental and applied, much less between good and bad. The result is that in the essay research loses a descriptive sense and becomes prescriptive. The essay implicitly becomes one of prescribing what research ought to be, in place of its purported intent to describe research in order to define library goals. (The words scholar and scholarship, by the way, are absent from the essay except where the concepts are described as obsolete; but they are not, and we as librarians have a responsibility to help assure that they do not become so.)

But let us assume the picture to be, in the main, true. Is it right? Is this the kind of research that should be done? More important, is it the only kind of research that should be done? And which researchers should we librarians aim best to serve, dedicated as we are to preserving, organizing, and providing the human heritage?

Clearly we need to serve all researchers, even bad ones, as best we can. That is not to say, however, that we must be passive components of the research process. For example, as research librarians we must take the stand that it is indeed important for national research collections to be built that aim at comprehensiveness, whether or not we call it an "ideal coverage of the entire structure of knowledge."

Libraries should not be market-driven institutions. While we need to take cognizance of current patterns of use and scholarship, we must also provide for the future and for the presently unfashionable. If some current researchers do not wish to use this cornucopia of knowledge, opinion, experience, and data, then that is their choice. We can have confidence that there are those who will; and even if there were not, we know that times change and that decades are a short term in the life of the mind, and therefore of libraries.

Miksa argues that we in the research libraries, and the researchers, are working at cross-purposes: "rather like two persons working in the same room, perhaps at tables near each other, supposedly on the same project, but without being fully aware of what each other is doing. ${ }^{117}$ His proposal to harmonize the two calls for libraries to change, to "more closely match the research actually being done." But from his description, it seems at least as desirable that instead, some research processes change.

I also do not think it appropriate for librarians to make up for the shortcomings of some current researchers by becoming handmaidens of their research teams. Librarians honorably share, with those who make use of knowledge, a division of scholarly labor: we serve to acquire, organize, preserve, and make accessible the body of human knowledge in all its recorded forms; we do this for scholars, who 
make the proper use of it. We have trained ourselves in valuable skills which researchers aren't required to have, and to discard these skills would be to break a link in the chain of knowledge transmission.

As an intellectual citizen, I am left profoundly uneasy by a description of researchers both unwilling and unable to review their own literature without our help. If the work is mechanical enough to be delegated, professional librarians should not be doing it-we need to do the difficult work of selection, organization, and preservation in the institutional repository, for no one else will. If the winnowing and searching is substantive enough, then the researcher should do it-or the label researcher loses meaning. A competent scholar in most fields should feel displaced and aggrieved by someone else doing what is fundamentally part of his or her job in "filtering" the appropriate information.

\section{WHAT SHOULD WE BE DOING?}

If I do not agree with the propositions that research libraries should narrow their collections to the work of the moment, and that research librarians should become information management team members on specific projects, what do I advocate should be our role? While we cannot expect directly to change the research patterns that are the result of great social and economic forces, we can have personal and professional effect. Both librarians and other scholars should be writing, in their journals and more broadly, about the value to society of maintaining the full human record in addition to the value of instantaneous availability of selected portions for selected scholars. Some of us may even wish to join Miksa and Osburn in asserting the imbalanced emphases of current research in the terms that they use, but with the aim of changing them rather than adapting to them.

In our libraries we need to argue for, and make, policy decisions that provide the research context that we believe is correct. This means relying on our professional knowledge and values as well as our sense of history, and not ceding only to the demands of the moment. There is a role here for bibliographers with faculty members and departments, and for senior library administrators in the highest councils of our universities. We will find allies among faculty and administrators who believe that there is value in research beyond specific investigation of particular problems.

At times we must make controversial decisions in collection development, provision of service points, separation or combination of collections, and allocation of staff resources. The result may be, for example, collection decisions that favor potential future research rather than specific current work; or staffing decisions in favor of preservation of existing materials rather than direct assistance in online searching, even as we make electronic information available in a variety of forms.

We need to understand the electronic information revolution so that we integrate it into our long-standing goal of providing broad information availability. If we ignore it, then we demonstrate that our heads are in the sand and we will have no credibility with researchers who need what it provides. If we respond only to the siren calls of immediacy, then we will lose touch with society's requirements for us to organize and preserve knowledge for the future.

We must become clearer about our responsibility to support at least two clienteles: today's scholars and tomorrow's. In the past what we did for the future scholar (collect, catalog, and preserve) more or less did the job for the present scholar. For years this has been less and less true as the immediacy of some literatures, and the immediate needs for them, have increased, while libraries have continued to provide best for monograph-oriented patrons. The wide availability of electronic information puts this contrast into high relief. Many research librarians are helping us to address this dual role; more of us should be. What we must not do is give up one clientele for the sake of the other. As Shirley Echelman says,

So here we librarians stand, Janus-like, guardians of the accumulated knowledge of the past and guides to the information upon which fu- 
ture knowledge will be built. . . . Without abrogating our responsibilities to our collections, we must harness the technical means ... . to the search for knowledge. ${ }^{18}$

We need to argue persuasively and rationally for more resources to do these new tasks. Since we will partially fail, as there are never enough resources to do all of what needs to be done, we must be prepared to make hard choices about what we can do and what we can't. ${ }^{19}$ These choices must be made in the context of our longterm goals, and not only to accede to the more pressing demands of our momentary clienteles, persuasive though they may be; we can hear from our future clienteles only through our own professionalism.

At the outset I said that Francis Miksa's stimulating paper needed to be discussed in terms of the underlying values and assumptions of our profession. He is right that what research libraries are doing no longer seems as it once did to match what researchers are doing. In the course of my appreciation of his perspectives, and my disagreements with his conclusions, I have introduced some value judgments to begin the discussion of why it is that we do what we do and what our goals are. As research librarians, we need to reformulate our goals and values and to debate them, for there will be disagreement. Many of us need to search again, through the clash of such debate, for conclusions that will help us guide our profession and therefore to shape future scholarship.

\section{REFERENCES AND NOTES}

1. Francis L. Miksa, Research Patterns and Research Libraries (Dublin: OCLC, c1987). Text of an address given at the Fifth Annual Conference of Directors of Research Libraries in OCLC, Mar. 30, 1987. (Available upon request from OCLC.)

2. Charles Osburn, Academic Research and Library Resources: Changing Patterns in America (Westport, Conn.: Greenwood, 1979).

3. Miksa, p.8.

4. Ibid., p.10.

5. Ibid., p.8.

6. Ibid., p.9.

7. Thomas S. Kuhn, The Structure of Scientific Revolutions (Chicago: Univ. of Chicago Pr., 1962).

8. Miksa, p.16, 19.

9. Ibid., p.9-10, 13.

10. Ibid., p.11.

11. Ibid., p.10.

12. Examples of research libraries orienting toward electronic information are many and include those of the following universities: Carnegie-Mellon, Vanderbilt, Georgia Tech, Columbia, Rutgers, Pennsylvania, California, Florida. For some descriptions see, among others, Caroline Arms, ed., Campus Networking Strategies (n.p., Digital, 1988), p.4, 70, pass.; and recent issues of the EDUCOM Bulletin.

13. For examples of some of the best thinking by librarians, see David Lewis, "Inventing the Electronic University," College \& Research Libraries 49:291-304 (July 1988); and Patricia Battin's articles, "The Electronic Library-A Vision of the Future," EDUCOM Bulletin 19:12-34 (Summer 1984) and "Crossing the Border: Librarianship in the Information Age," The Harvard Librarian 19:8-10 (Sept. 1985). See also B. B. Siman, "Machine-Readable Data Files in the Library," Technicalities 6:6 June 1986); and Richard W. McCoy, "The Electronic Scholar: Essential Tasks for the Scholarly Community," Library Journal 110:39-42 (Oct. 1, 1985).

14. Miksa, p.11.

15. Ibid., p.12.

16. Ibid., p.13.

17. Ibid., p.12.

18. Shirley Echelman, "Why do Academic Libraries Get Such a Bad Rap?" Library Journal 113:39-41 (Oct. 1, 1988).

19. For a perceptive discussion of the importance of making resource choices, see Paul Metz, "Special Pleading versus Self-Discipline in the Financing of Public Services," Journal of Academic Librarianship 14:208-13 (Sept. 1988). 